bias to such studies and especially the study of the British Commonwealth of Nations, as an example of a new kind of political association between free and independent peoples, based on principles which are universally and permanently valid.

\section{Beneficial Employment and Vocational Guidance}

LOCAL education authorities will, next year, be called upon to consider applications for exemption from compulsory school attendance of children between fourteen and fifteen years of age and to determine in each case whether the employment proposed will be "beneficial" to the child. The Board of Education has suggested to local authorities, among other measures for qualifying themselves for determining these difficult questions, the requirement of a school report indicating the child's good, average and weak subjects and information regarding manual or domestic training received, and a medical report expressing the doctor's opinion as to the types of occupation unsuitable for the child-hence a widespread stimulation of interest in the principles and practice of vocational guidance, a subject in which there has been a large amount of research in America. The United States Office of Education, with the assistance of the National Occupational Conference, has prepared bibliographies of current literature in this field and recently published a "Guidance Bibliography" (Bulletin No. 37. Washington, D.C. : Supt. of Documents. 10 cents), an annotated list of 442 books, pamphlets and periodical references classified under the headings : elementary schools, secondary schools, colleges, adult and out-of-school youth, and techniques and procedures. Information as to careers is published monthly by the National Occupational Conference in an "Occupational Index".

\section{The English Sprat Fishery}

The Ministry of Agriculture and Fisheries paper by Mr. J. Armitage Robertson on "The Sprat and the Sprat Fishery of England" (Fisheries Investigations. Series 2, 16, No. 2) deals with the economic importance of the sprat, the location of the fishery, behaviour and geographical distribution, life-history, age, sexratio and food. Even the health of the sprat is treated in a section devoted to 'parasites and disease', from which the sprat seems tolerably immune. The fishery is a localized inshore winter one, confined to the south coast and East Anglian seaboard, and is prosecuted in a variety of ways : by drift nets, stownets, trawls and seine nets. The possibility that the shoals are 'driven' shoreward by the incursion during the winter months into the Southern Bight of the North Sea of water of a higher salinity (greater than 35 per mille) than that to which they are accustomed is discussed, but Mr. Robertson is insufficiently convinced by the available data on this point and considers "that these hydrographical conditions and the circumstances of the fishery do not bear the relation of cause and effect, but are merely due to some general and common cause such as 'Winter Conditions'". In spite of a Norwegian authority's statement that English sprats are "tough, coarse and unpalatable", Mr. Robertson finds nothing to support this, and recommends as beneficial both to the fishery and to the country the development of the already existing small sprat-canning industry in Great Britain. English prices vary between $3 s$. and $16 s$. per cwt., whereas the average cost of imported canned brisling, mostly from Norway, is $£ 613 s$. per cwt., so that the industry should have an ample working margin.

\section{Radio Interference by Electro-Medical Apparatus}

IN a recent article in NATURE (May 21, p. 941), attention was directed to the widespread interference caused to radio reception by various classes of electrical apparatus. One of the sources of such interference and also one of the most difficult to mitigate is a certain type of electro-medical apparatus used for diathermy treatment. With the view of securing an amelioration of conditions in this field, the PostmasterGeneral has asked the Minister of Health to direct the attention of local authorities to this matter. Accordingly a circular letter has been issued by the Ministry of Health to all local councils, including welfare and local education authorities (Circular 1695). With this circular was enclosed a memorandum prepared by the Radio Branch of the Post Office on the prevention of interference with radio reception from certain types of electro-medical apparatus. This memorandum has been reprinted from The Hospital, the official organ of the British Hospitals Association. It is to be noted that modern valve-rectified $\mathrm{X}$-ray apparatus is not likely to cause interference; and the memorandum is primarily concerned with certain diathermy installations working on medium waves, short waves, and ultra-short waves which can only be prevented from causing interference by the addition of an electrical screen or Faraday cage capable of enclosing not only the apparatus but also the patient and the operator. Since no other effective method of prevention has yet been discovered, it seems desirable that, for new hospital buildings or extensions of existing hospitals or other new buildings in which these forms of apparatus are likely to be used, the inclusion of screened rooms should be considered. Attention is directed to the fact that the Radio Branch of the Post Office is prepared to advise on any problem arising and also on the prevention of interference from existing plant.

\section{The Cheshunt Research Station}

THE annual report for 1937 of the Experimental and Research Station at Turner's Hill, Cheshunt, Herts, announces a new auxiliary venture. It was recognized that the control of virus diseases of cucumbers and tomatoes could only be accomplished by the use of seed from disease-free plants. A Seed Growers' Association is therefore to be formed to carry on this commercial side of the Station's activity. A capital of $£ 3,000$ has been subscribed, and will enable the venture to start. Many experimental trials which have been prosecuted in previous years are continued to give conclusive results. Such 